IOS Press

\title{
Erratum
}

\section{Memory Binding Test Predicts Incident Amnestic Mild Cognitive Impairment}

\author{
Wenzhu B. Mowrey, Richard B. Lipton, Mindy J. Katz, Wendy S. Ramratan, \\ David A. Loewenstein, Molly E. Zimmerman and Herman Buschke
}

[Journal of Alzheimer's Disease 53(4), 2016, 1585-1595, DOI: 10.3233/JAD-160291]

http://content.iospress.com/articles/journal-of-alzheimers-disease/jad160291

In the article, the variable called the number of Pairs In the Paired condition (PIP) was mischaracterized, though the main conclusions are not altered. The incorrect PIP measure included in the publication was the number of pairs scored based on single items cued recalled from List 1 and List 2 under the single list recall condition, not the number of pairs recalled under the paired condition. Reanalysis was performed.

On page 1588, the baseline PIP values should be corrected in Table 1 (corrected Table 1 included below, the corrected numbers are in bold font).

The last sentence in the main text on Page 1590, left panel, which was:

"Binding measure PIP was predictive using cut-scores of 8 and $9(p \leq 0.01)$ but not predictive using the cut-scores of 10 and 11 ( $p=0.07$ and 0.51 , respectively)".

Should instead read:

"Binding measure PIP was predictive using cut-scores of $6(p=0.03)$ and $7(p=0.006)$ but not predictive using the cut-scores of $8,9,10$ and $11(p>0.10)$ ".

Supplemental Tables 2, 3, 4, 5 and 8 were also revised (the revised supplemental file is available with the original article as published in the journal). 
Table 1

Baseline characteristics for the whole sample and for groups stratified by incident aMCI status at follow-up ${ }^{\mathrm{a}}$

\begin{tabular}{|c|c|c|c|c|}
\hline Variable & $\begin{array}{c}\begin{array}{c}\text { Cognitively } \\
\text { Normal at Baseline }\end{array} \\
(n=246)\end{array}$ & $\begin{array}{c}\text { No } \\
\text { Incident aMCI } \\
(n=198) \\
\end{array}$ & $\begin{array}{c}\text { Incident } \\
\text { aMCI } \\
(n=48)\end{array}$ & $p$ value $^{\mathrm{b}}$ \\
\hline Age, mean (SD), years & $79.7(4.6)$ & $79.3(4.5)$ & $81.5(4.6)$ & 0.003 \\
\hline Female, $\%$ & 59.4 & 58.6 & 62.5 & 0.62 \\
\hline \multicolumn{5}{|l|}{ Race, \% } \\
\hline White & 67.9 & 68.7 & 64.6 & \\
\hline Black & 27.6 & 26.3 & 33.3 & 0.51 \\
\hline Other & 4.5 & 5.0 & 2.1 & \\
\hline Years of Education & $13.8(3.4)$ & $13.9(3.5)$ & $13.4(3.2)$ & 0.19 \\
\hline WRAT-3 & $11.4(2.3)$ & $11.5(2.2)$ & $11.0(2.6)$ & 0.23 \\
\hline GDS score & $2.1(2.2)$ & $2.0(2.1)$ & $2.8(2.4)$ & 0.01 \\
\hline \multicolumn{5}{|l|}{ Cumulative CVD events, \% } \\
\hline 0 CVD event & 82.1 & 83.8 & 75.0 & \\
\hline $1 \mathrm{CVD}$ event & 16.7 & 15.7 & 20.8 & 0.08 \\
\hline 2 CVD events & 1.2 & 0.5 & 4.2 & \\
\hline BIMC & $1.9(1.9)$ & $1.8(1.9)$ & $2.4(2.1)$ & 0.03 \\
\hline MBT CR-L1 & $14.4(1.7)$ & $14.5(1.5)$ & $13.8(2.3)$ & 0.13 \\
\hline MBT CR-L2 & $11.6(2.9)$ & $11.8(2.8)$ & $10.5(2.9)$ & 0.004 \\
\hline MBT PIP & $9.9(3.8)$ & $10.3(3.6)$ & $8.6(3.9)$ & 0.008 \\
\hline MBT TIP & $24.9(5.0)$ & $25.4(4.6)$ & $22.8(5.8)$ & 0.004 \\
\hline FCSRT-FR $^{\mathrm{c}}$ & $32.8(5.6)$ & $33.6(5.0)$ & $29.3(6.6)$ & $<0.0001$ \\
\hline $\mathrm{LM}-\mathrm{I}^{\mathrm{c}}$ & $22.1(7.1)$ & $22.9(7.0)$ & $19.0(6.6)$ & 0.0007 \\
\hline Follow up, median (IQR), years & $3.8(1.0,6.7)$ & $3.9(1.1,6.9)$ & $2.9(0.9,5.7)$ & 0.41 \\
\hline
\end{tabular}

Abbreviations: aMCI=amnestic Mild Cognitive Impairment; WRAT-3=Wide Range Achievement Test-Third Edition reading subtest grade score; GDS $=$ Geriatric Depression Scale; CVD $=$ Cardiovascular disease; BIMC $=\mathrm{Blessed}$ Information-Memory-Concentration test; MBT = Memory Binding Test; CR-L1 = Number of items Cued Recalled from List 1 on the MBT; CR-L2 = Number of items Cued Recalled from List 2 on the MBT; PIP = Number of Pairs cued recalled In the Paired condition on the MBT; TIP = Total number of Items cued recalled in the Paired condition on the MBT; FCSRT-FR = the Free and Cued Selective Reminding Test free recall; LM-I = Logical Memory I. ${ }^{a}$ This sample included 246 participants who were cognitively normal at baseline. The corresponding results including participants who were cognitive normal and naMCI at baseline are shown in Supplementary Table $4 .{ }^{\mathrm{b}}$ Wilcoxon-Mann-Whitney tests were used to compare the continuous variables while Pearson's Chi square tests and Fisher's exact tests were used to compare categorical variables. ${ }^{\mathrm{c}}$ These results may be circular because the FCSRT-FR and LM-I were available to the diagnosticians assigning a diagnosis at case conference. 